\title{
Community Physiotherapy and Rehabilitation in Bangladesh
}

\author{
Renesa Sarah Anny ${ }^{1}$ and Md Monoarul Haque ${ }^{2 *}$ \\ ${ }^{1}$ Physiotherapist, Bangladesh Institute of Health Sciences Hospital, Bangladesh \\ ${ }^{2}$ Fareast International University, Bangladesh \\ *Corresponding author: Monoarul Haque, Fareast International University, Bangladesh. \\ To Cite This Article: Renesa Sarah Anny, Md Monoarul Haque*. Community Physiotherapy and Rehabilitation in Bangladesh. Am J Biomed Sci \\ \& Res. 2019 - 1(4). AJBSR.MS.ID.000537. DOI: 10.34297/AJBSR.2019.01.000537
}

Received: February 15, 2019 | Published: February 26, 2019

\section{Editorial}

Community Physiotherapy is totally a new concept and less pursued specialization in physiotherapy (Rajan, 2013). This might be due to various reasons; to name a few, the lack of interest among physiotherapist to work in the communities, paucity of information on community-based physiotherapy, complex methods required to measure a community and reduced awareness about community health problems among physiotherapists (Rajan, 2012). Bangladesh is a developing country with a huge population, in that case community-based physiotherapy can be a perceived as an important cog in the wheel of the healthcare system. Although, in Bangladesh, Graduate physiotherapists have lack of interest in community based of physiotherapy due to lack of information about it. Here center-based physiotherapy is very popular and maximum physiotherapists want to settle in urban areas due to a good or comfort life with a good income. Center based physiotherapy depends on equipment, electricity, a lot of space etc and this center is run by a qualified physiotherapist. But the absolute growth of the disabled population in Bangladesh is approximately 25000 (Impact Foundation Bangladesh, 2002).

These are more approximately 6 times more people with disabilities in rural areas (Japan International Co-operation Agency Planning and Evacuation Department, 2002). In this condition, community-based physiotherapy can be beneficial. It can be economical or non-economical. Economic benefits are those benefits that can be quantified, usually in monetary terms, while non-economic benefits are less tangible and are usually difficult to express in quantitative term. Another economic benefit derived from community-based physiotherapy is better health for people in the employable age group, resulting in increased productivity and greater economic gains for the country. Chronic diseases can be considered as "an economic burden to the community". Thus, the community-based physiotherapy to identify health problems, especially among those "productive" age group, can indirectly aid in income generation in the country. It has also been seen that community interventions among school-going children promote better health and reduce absenteeism at school (Limerick Health Promotion, 2008).

Children are the adults of the future, and community interventions for school children could help to build a healthier and more productive adult workers. Now a days many organizations work on it. Government and non-government organizations try to help rural peoples by providing community-based physiotherapy. They are launching different type project as community based. But there is limited research available on community physiotherapy in Bangladesh as well as Asia. So, the benefits of community physiotherapy are less known to people of rural side and also among physiotherapists. By establishment of community physiotherapy in large scale, can possible to treat health conditions at initial stage and preventing chronicity. And also, possible give attention to the people who are simply deprived of other health related facilities. Community Physiotherapy can also be a way to create awareness among people about disability, chronic health conditions, degenerative changes which will be beneficial for people as well as economic conditions of Bangladesh. 